\title{
Modeling high-impact weather and climate: lessons from a tropical cyclone perspective
}

\author{
James M. Done • Greg J. Holland • Cindy L. Bruyère • \\ L. Ruby Leung • Asuka Suzuki-Parker
}

Received: 22 January 2013 / Accepted: 17 September 2013 / Published online: 19 October 2013

(C) The Author(s) 2013. This article is published with open access at Springerlink.com

\begin{abstract}
Although the societal impact of a weather event increases with the rarity of the event, our current ability to assess extreme events and their impacts is limited by not only rarity but also by current model fidelity and a lack of understanding and capacity to model the underlying physical processes. This challenge is driving fresh approaches to assess highimpact weather and climate. Recent lessons learned in modeling high-impact weather and climate are presented using the case of tropical cyclones as an illustrative example. Through examples using the Nested Regional Climate Model to dynamically downscale large-scale climate data the need to treat bias in the driving data is illustrated. Domain size, location, and resolution are also shown to be critical and should be adequate to: include relevant regional climate physical processes; resolve key impact parameters; and accurately simulate the response to changes in external forcing. The notion of sufficient model resolution is introduced together with the added value in combining dynamical and statistical assessments to fill out the parent distribution of high-impact parameters.
\end{abstract}

\section{Introduction}

In recent years, society has faced a steep rise in economic and insured losses from weather and climate related hazards, largely due to significant increase in exposure (e.g. Kunreuther

This article is part of a Special Issue on "Regional Earth System Modeling" edited by Zong-Liang Yang and Congbin Fu.

Electronic supplementary material The online version of this article (doi:10.1007/s10584-013-0954-6) contains supplementary material, which is available to authorized users.

J. M. Done $(\bowtie) \cdot$ G. J. Holland • C. L. Bruyère

NCAR Earth System Laboratory, P.O. Box 3000, Boulder, CO 80307, USA

e-mail: done@ucar.edu

C. L. Bruyère

Environmental Sciences and Management, North-West University, Potchefstroom, South Africa

L. R. Leung

Pacific Northwest National Laboratory, PO Box 999, Richland, WA 99352, USA

A. Suzuki-Parker

University of Tsukuba, 1-1-1 Tennodai, Tsukuba, Ibaraki 305-8577, Japan 
and Michel-Kerjan 2009). Projections of a continuing trend towards more intense systems (see Knutson et al. 2010; Holland and Bruyère 2013 for the case of tropical cyclones) point to a further increase in societal vulnerability. More accurate information on high-impact events, is thus a critical need of society. This requires assessments of the statistics of highimpact events and the associated uncertainty with regional clarity together with potential changes under climate variability and change.

Meeting these demands requires a combination of dynamical and statistical components. The traditional dynamical approach combines the capacity of regional high resolution to simulate weather events with the capacity of global coarse resolution to simulate climate by embedding high resolution within the global mesh over regions of interest (e.g. Laprise et al. 2008; Knutson et al. 2007). Increases in computational capacity have enabled such simulations in unprecedented detail (e.g. Bender et al. 2010). Regional modeling studies are subject to uncertainty and careful consideration is required of the balance between model complexity to resolve the relevant physical processes, ensemble size to sample uncertainty in the driving data, and simulation length to capture the full distribution. These competing demands for computational resources often results in a truncation of the full distribution of high-impact events and this has led to exploration of a variety of solutions including the use of empirical relationships between weather systems and the large-scale environment (e.g. Camargo et al. 2007), and assessment of errors in frequency distributions of weather events from dynamical models (e.g. Katz 2010).

Meeting the societal demand of assessing high-impact events with regional clarity remains extremely challenging. This paper presents an overview of recent lessons learnt in modeling high-impact events on regional scales using the case of tropical cyclones. Tropical cyclones represent a hard test case for simulating high-impact weather owing to their rarity, regional variability and uncertain future regional changes (see for example large variations between the modeling studies of Knutson et al. 2007, 2010 and Bengtsson et al. 2007). The merits and limitations of the dynamical modeling approach are discussed and motivate, by way of illustrative examples, the need for combined dynamical-statistical approaches in order to provide credible and useful information.

The next section describes simulation experiments with the Nested Regional Climate Model (NRCM), a dynamical downscaling tool based on the Weather Research and Forecasting (WRF) model (Skamarock et al. 2008) designed specifically to contribute to assessments of high-impact events. Atmosphere-only NRCM simulations of current and future North Atlantic tropical cyclone activity are presented to illustrate current limitations and sensitivities of the dynamical model approach. The value of complementary statistical approaches is illustrated in Section 3. Finally, key findings are summarized in Section 4.

\section{Dynamical assessments}

Here multi-year NRCM simulations of high-impact weather are assessed using limited area domains to identify the impact of climate bias, domain size and resolution; and to explore and document critical sensitivities of this dynamical modeling approach.

Global climate data are provided by Community Climate System Model (CCSM, Collins et al. 2006) version 3 using the A2 scenario (IPCC SRES SPM 2000), from the Coupled Model Intercomparison Project 3 (CMIP3, Meehl et al. 2007). The CCSM is a full Earth system model, including atmosphere, ocean, cryosphere, biosphere, and land surface. These data are used to drive a NRCM $36 \mathrm{~km}$ domain using one-way nesting, which in turn is used to drive a $12 \mathrm{~km}$ domain (Fig. 1) to explore the additional information, if any, provided by 
the higher resolution. One-way nesting is chosen to avoid the unknown implications of using two-way nesting and for the practical reason of running each domain separately and checking the simulation prior to further downscaling. A description of the NRCM and physics used is provided in the supplemental online material (SOM) section S1.

The simulations cover three periods: a decade of 'current' climate conditions (1995-2005) referred to hereafter as 'base climate', and two future decades of 2020-2030 and 2045-2055. The time periods are nominal since the driving CCSM model was initialized in 1950 with no additional assimilated data. Thus, for example, model interannual and multidecadal variations are not expected to match those in the real world, though the historical anthropogenic trend associated with greenhouse gases should be captured.

\subsection{Domain size, location and horizontal resolution}

Domain size and horizontal resolution are key factors for regional climate simulation (e.g. Vannitsem and Chome 2005) and tropical cyclone simulation (e.g. Kumar et al. 2011). High resolution is required to adequately resolve the intensity of strong tropical cyclones (Bender et al 2010), particularly if they are small. Resolution also affects cyclone structure (Fig. 2). At $36 \mathrm{~km}$ the simulated cyclone has a simple circular structure whereas at $12 \mathrm{~km}$ sub-systemscale structure emerges in the form of eye-wall asymmetries and spiral rain bands. As the grid-spacing is reduced further the shift from parameterized towards explicit convection can additionally impact other cyclone characteristics including; genesis mechanism (Kieu and Zhang 2008), eye-wall replacement cycles and rapid intensification (Davis et al. 2008), and upscale impacts through vertical redistributions of heat and momentum (as discussed in Leung et al. 2006). Finally, cyclone frequency is also found to be sensitive to resolution (SOM text, section S3). Whether this is due to changes in small- or large-scale processes is unknown. Caron et al. (2010) and Caron and Jones (2011) found high resolution was necessary for the intensity of easterly waves and even for accurate representation of the large-scale environment over the eastern Atlantic.

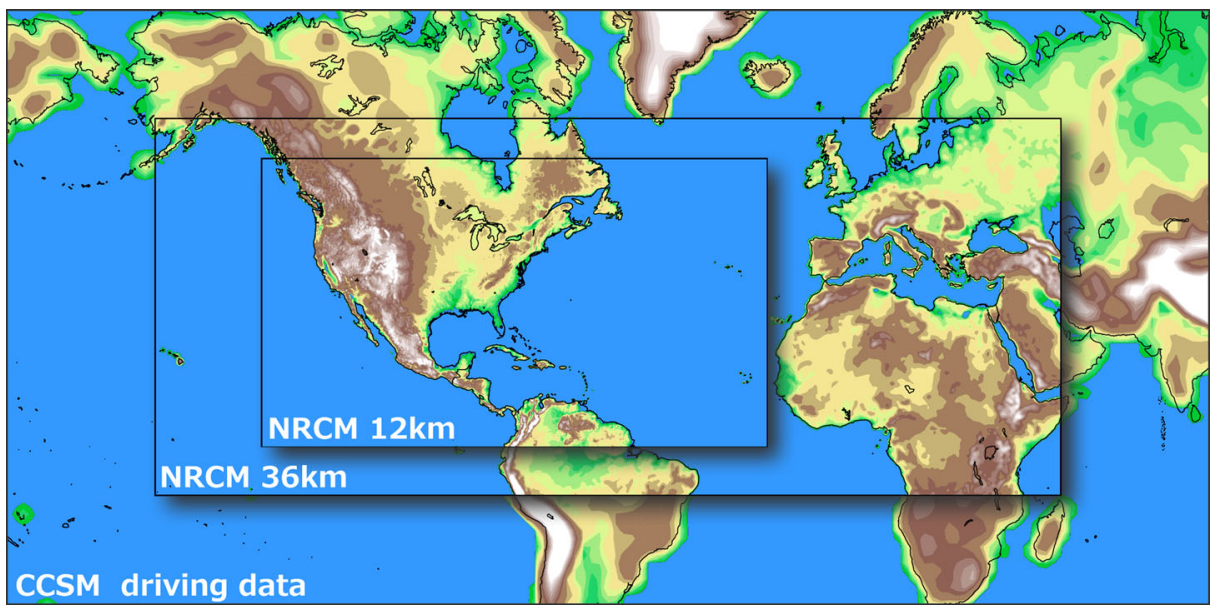

Fig. 1 NRCM model domains at $36 \mathrm{~km}$ grid spacing (large black box) and $12 \mathrm{~km}$ grid spacing (small black box). Model terrain height (shaded) is shown at the different model resolutions and extends beyond the $36 \mathrm{~km}$ domain to indicate the resolution of the driving CCSM. Adapted from Done et al (2011). Copyright 2011 OTC. Reproduced with permission of the copyright owner 

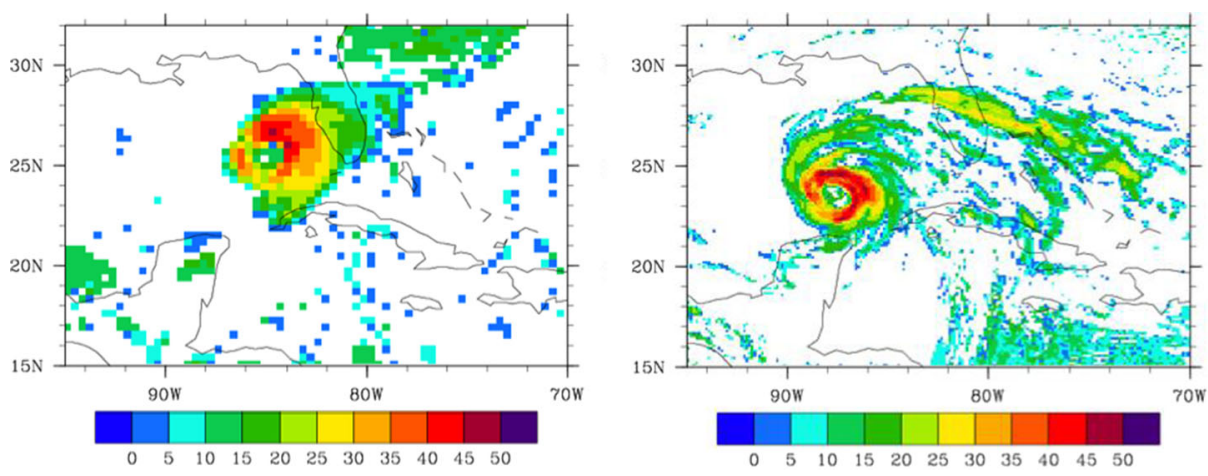

Fig. 2 Snapshots of example NRCM simulated tropical cyclones in the Gulf of Mexico generated on (left) the $36 \mathrm{~km}$ grid and (right) the $12 \mathrm{~km}$ grid, shown in model derived radar reflectivity $(\mathrm{dBz})$

Large nested domains have been shown to improve the simulation of all scales within the domain interior above those in the driving global data (Jones et al. 1995; Laprise et al. 2008) and reduce spatial spin-up issues by moving the inflow boundary far from the region of interest (Leduc and Laprise 2009). Critically, the domain needs to be sufficiently large to capture regional physical processes (Giorgi and Mearns 1999) not only to assess high-impact weather in current climate but also to capture the correct climate response. A domain that is smaller than the main external modes of variability is closely coupled to the driving model (somewhat similar to nudging), and where small scales are important to these modes, the domain size needs to be large to enable this upscale interaction to occur. For example, Caron and Jones (2011) constructed a domain to capture relationships between Atlantic SSTs, Sahelian rainfall and tropical cyclogenesis.

Guided by these findings, available resources for this study are directed to domain size and resolution at the expense of run length and ensemble size so a single simulation is run on each domain. The 36 and $12 \mathrm{~km}$ domains are far larger than North America, our target region, to ensure the majority of atmospheric processes that impact the region are handled by the higher resolution model rather than the coarser climate model. As a specific example, African easterly waves are not well captured by the CCSM simulation, necessitating the inclusion of the African wave source and development region within the $36 \mathrm{~km}$ domain (see SOM section S3 for discussion on the representation of easterly waves).

\subsection{Climate bias}

Global climate models commonly contain climate bias and despite the large domain, the NRCM-generated climate driven directly by CCSM data contains substantial biases. Anomalously strong large-scale flow at upper-levels over the tropical North Atlantic produces strong vertical wind shear, defined as the difference in winds between 200- and 850$\mathrm{hPa}$ (Fig. 3a), thereby preventing tropical cyclogenesis. Sensitivity studies (not shown) reveal that this bias is transferred to the NRCM from CCSM, in part due to dynamical propagation from the east and west boundaries but also due to a warm eastern Pacific Ocean SST bias (Large and Danabasoglu 2006). This permanent El Niño-like condition contributed

Fig. 3 Three-month average vertical wind shear $\left(200-850 \mathrm{hPa}, \mathrm{ms}^{-1}\right)$ for the period August-October 1996 for a NRCM driven by raw CCSM data; b NRCM driven by revised CCSM data; $\mathbf{c}$ raw CCSM data, and $\mathbf{d}$ NNRP data. Adapted from Holland et al (2010). Copyright 2010 OTC. Reproduced with permission of the copyright owner 


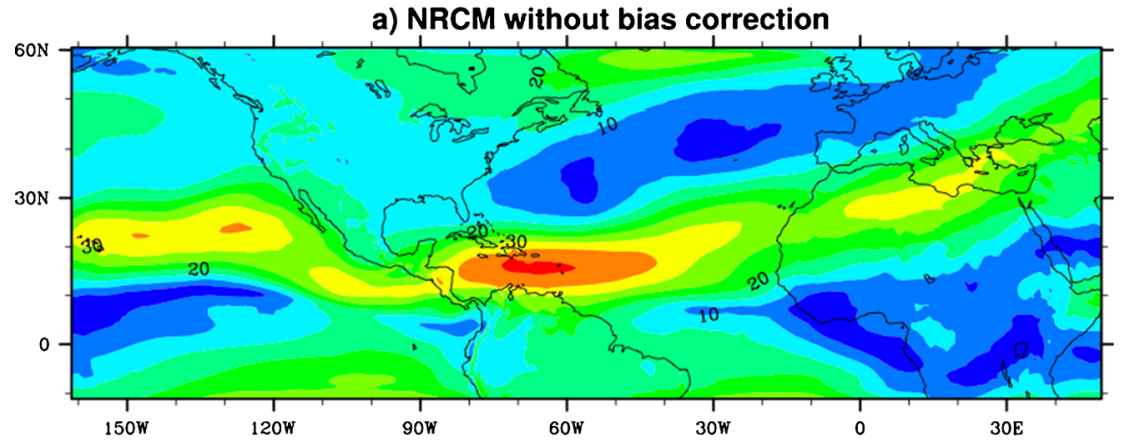

b) NRCM with bias correction

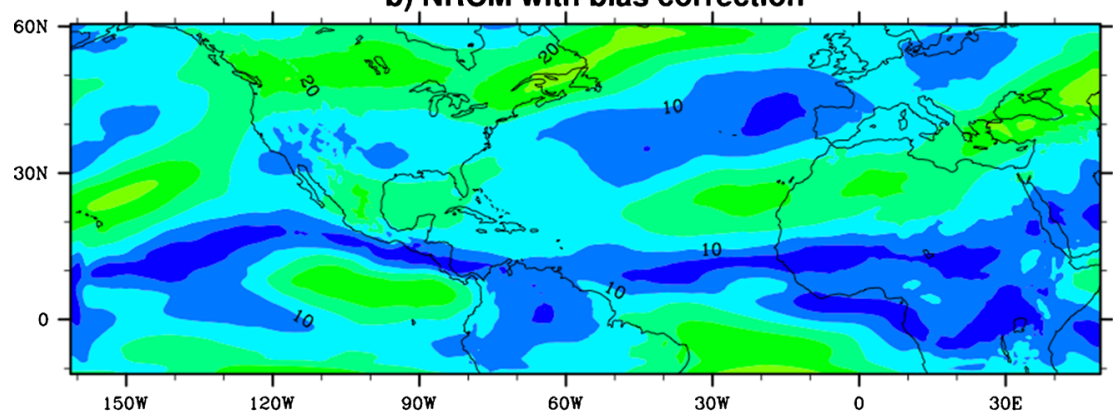

c) CCSM

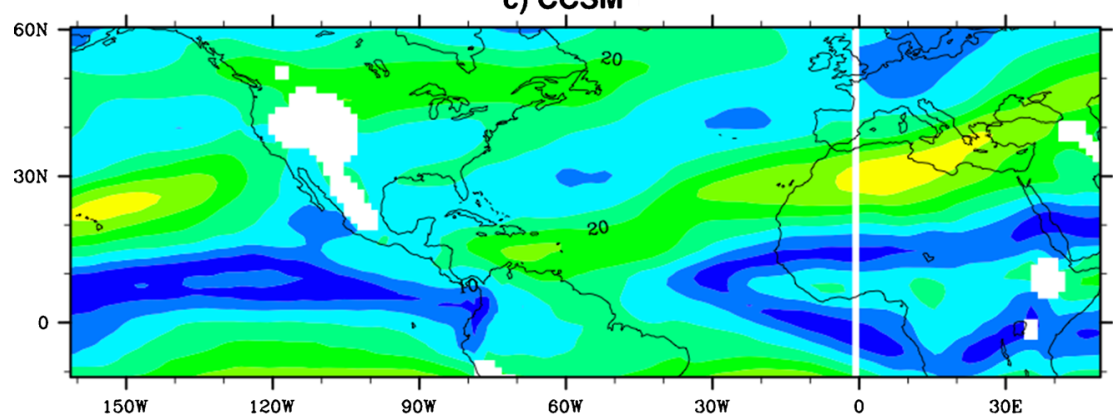

d) Observation

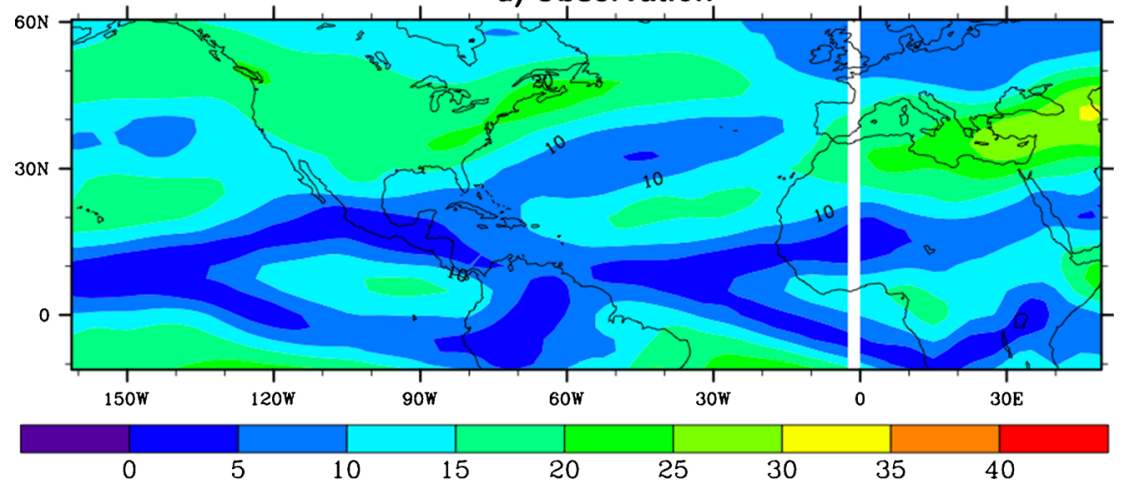


to the high vertical wind shear in the NRCM over the tropical Atlantic through a modified Walker Circulation (e.g. Gray 1984). One approach to correcting bias is to statistically correct the NRCM model output (Dosio and Paruolo 2011) but here this post-processing approach is not suitable since the biased climate did not generate any tropical cyclones, thereby necessitating bias correction of the driving CCSM data prior to NRCM simulation.

A popular approach to assessing regional climate change that implicitly removes bias is the pseudo-global-warming approach (Schär et al. 1996; Rasmussen et al. 2011). In this approach, reanalysis data are used for current climate and future climate is constructed by adding a perturbation, intended to represent the mean climate change, to the reanalysis data. This approach assumes no change in variability at the domain boundaries and for small domains will constrain the frequency of weather events to current climate only. An alternative bias correction technique is used here that allows synoptic and climate variability to change in the future. Six-hourly CCSM data for the entire simulation (1950-2100) are broken down into an average annual cycle plus a perturbation term:

$$
C C S M=\overline{C C S M}+C C S M^{\prime}
$$

where $C C S M^{\prime}$ varies in time throughout the entire 150-year CCSM simulation period and includes both high-frequency variability and climate trends. The average annual cycle is defined over a 20-year base period (to smooth out any influence of El Niño) from 1975 to 1994. Twenty years may not be sufficient to smooth out influence of multi-decadal variability but is chosen to avoid inclusion of any climate trends. Similarly, 6-hourly NCEP/NCAR Reanalysis Project (NNRP, Kalnay et al. 1996) data for 1975-1994 are broken down into an average annual cycle plus a perturbation term:

$$
N N R P=\overline{N N R P}+N N R P^{\prime},
$$

The revised climate data, $C C S M_{R}$, are then constructed by replacing $\overline{C C S M}$ in Eq. 1 with $\overline{N N R P}$ in Eq. 2:

$$
C C S M_{R}=\overline{N N R P}+C C S M^{\prime},
$$

$C C S M_{R}$ therefore combines a base, seasonally varying climate provided by reanalysis data with day-to-day weather, climate variability (e.g. synoptic weather systems, ENSO) and climate change provided by CCSM. This approach is similar to the method used by $\mathrm{Xu}$ and Yang (2012) that additionally corrects for variability bias. We choose here to correct only the mean bias, specifically to reduce the strong wind shear. Although the variance in $C C S M^{\prime}$ is generally slightly smaller than $N N R P^{\prime}$ over the base period, the regional model driven by $C C S M_{R}$ recovers this difference in variance (not shown). Equation 3 is applied to variables needed to generate the lateral boundary conditions for NRCM; zonal and meridional wind, geopotential height, temperature, relative humidity, mean sea level pressure, and lower boundary condition of sea surface temperature. When driven by revised boundary conditions, the NRCM develops substantially improved wind shear over the tropical Atlantic (Fig. 3).

There may be sensitivity of the revised climate to the choice of the base period arising from non-stationarity of the bias, but fortunately this is not the case here. Sensitivity studies using different base periods result in nearly identical bias corrections over the entire simulation period. This increases confidence that the bias will not change substantially in the future, though the validity of this assumption needs further consideration. Further justification for this approach is provided by Mote et al. (2011), who showed that for assessing changes between a 
current and future period, a biased model for current climate is as valid as an unbiased model. On the other hand, Dosio and Paruolo (2011) showed the assumption of constant bias in time may only be appropriate for ensemble mean quantities rather than for individual model projections.

\subsection{Future changes in tropical cyclone frequency}

NRCM simulated tropical cyclones are identified and tracked automatically following Suzuki-Parker (2012) and described briefly in the SOM section S2. On the $36 \mathrm{~km}$ domain the NRCM driven by revised CCSM data produces an average of 7.6 North Atlantic tropical cyclones annually for base climate. As noted earlier the model base climate period 19952005 is nominal. This introduces ambiguity as to the selection of observational period used for model evaluation. The selection of 1975-1994 as base period for the bias correction leads to this being one logical choice. In this case the comparative annual number of observed North Atlantic named tropical cyclones (including tropical storms and hurricane categories 1-5) is 8.9 (using IBTrACS data, Knapp et al. 2010). Alternative choices are the average over, say, the recent 50 years (1958-2007) of 10.4, or the current (1995-2005) high period of 14.3 cyclones per year. Regardless of the choice of observational period for comparison, NRCM appears to underestimate the actual frequency. This frequency underestimate could easily be corrected by tuning the detection criteria but the detection parameters are deliberately frozen at fixed values. Of importance to this study, Suzuki-Parker (2012) showed that the future changes in cyclone frequency are not impacted by the choice of detection values.

The NRCM predicts an increase in North Atlantic tropical cyclone frequency, with annual numbers on the $36 \mathrm{~km}$ domain increasing from 7.6 in the base climate to 8.5 in 2020-2030 and 10.4 in 2045-2055. This is a statistically significant increase (using the Wilcoxon-MannWhitney rank-sum test, Wilks (2006)) at the $90 \%$ level and represents a $37 \%$ increase in North Atlantic tropical cyclone frequency over the next 50 years. Annual numbers of cyclones on the $12 \mathrm{~km}$ domain, using the same detection criteria as for $36 \mathrm{~km}$, are higher at 17.3, 17.5 and 19.9 for the three time slices, but show a similar increase (though not significant) of $15 \%$ over the next 50 years. These results are different from those of other studies, which have tended towards predicting small changes and if anything a decrease in overall Atlantic tropical cyclone frequency over coming decades (e.g. Knutson et al. 2010; Bengtsson et al. 2007), and serves to highlight the large uncertainty in determining changes in high-impact events on regional scales.

The modeled spatial distribution of North Atlantic tropical cyclone track and genesis densities on both the 36- and $12 \mathrm{~km}$ domains for base climate are close to the observed longterm climatology (Fig. 4). The future climate prediction exhibits a consistent southeastward shift in track density, from a maximum in the mid-Atlantic in base climate, to a low-latitude maximum in 2045-2055 (Fig. 4). This prediction is a continuation of recent trends (Holland and Webster 2007) and agrees with Wu et al. (2010) who found that a relative increase in eastern Atlantic SSTs leads to changes in atmospheric circulation and near-equatorial tropical cyclone activity.

\subsection{Future changes in tropical cyclone intensity}

Modeled tropical cyclone intensity distributions show the most intense cyclones are weaker than observed (Fig. 5). This is a common problem due to the inability of the 36- and $12 \mathrm{~km}$ grids to resolve the inner core dynamics of a tropical cyclone (e.g. Knutson et al. 2008; Davis et al. 2010; Gentry and Lackmann 2010). Note also the related tendency to over-simulate moderate intensity systems, which to some extent is due to those storms that would have been more intense being 


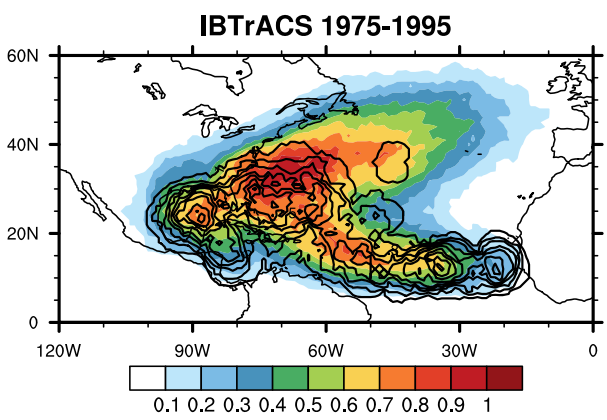

36km 1995-2005

$12 \mathrm{~km} \mathrm{1995-2005}$

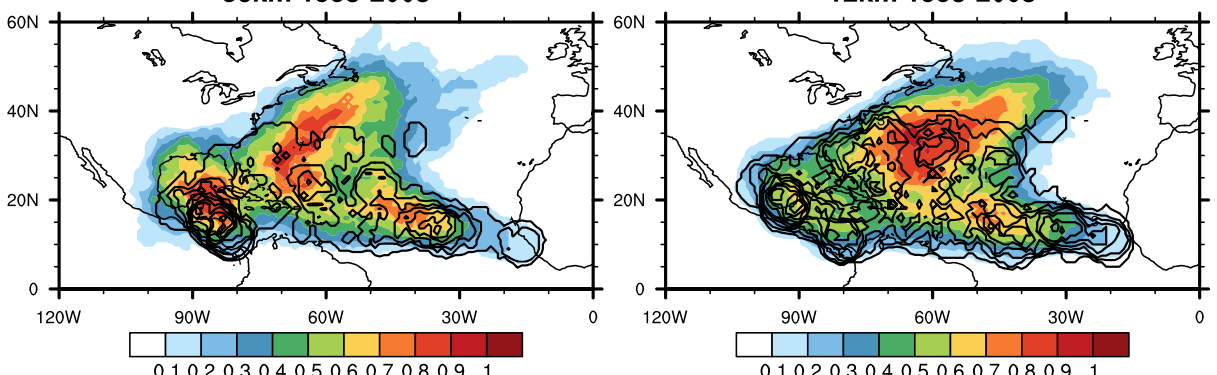

$36 \mathrm{~km} \mathrm{2020-2030}$

$12 \mathrm{~km} \mathrm{2020-2030}$

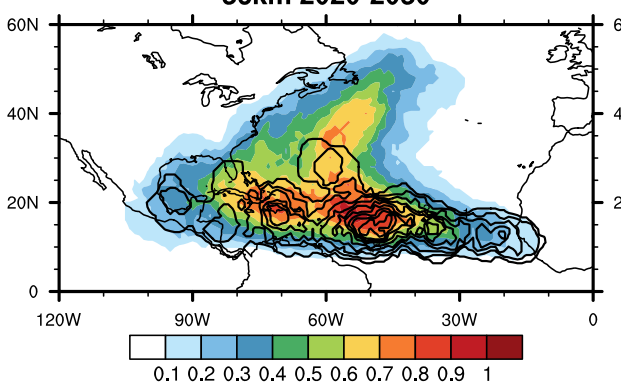

36km 2045-2055
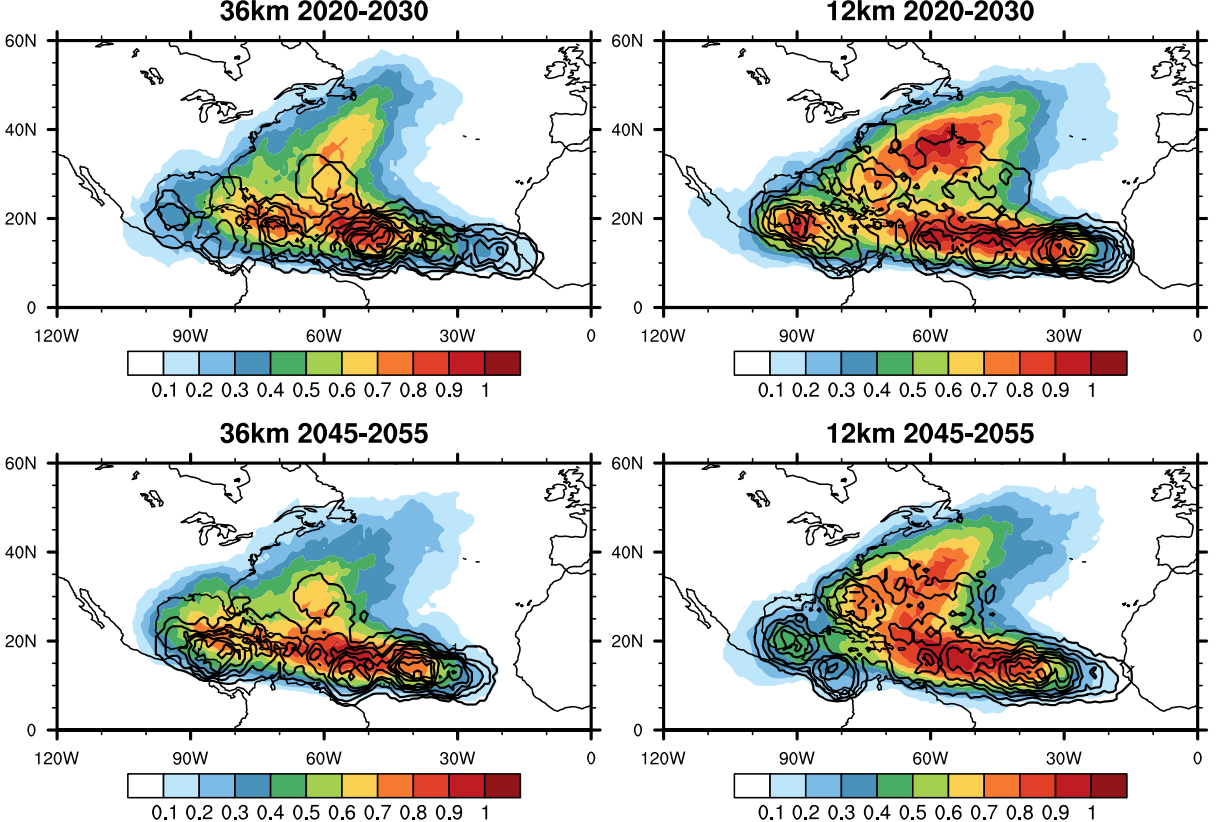

Fig. 4 Tropical cyclone track density (color shading) and genesis density (contours) normalized by the maximum value for (top) IBTrACS data 1975-1995, (left column) NRCM $36 \mathrm{~km}$ domain, (right column) NRCM $12 \mathrm{~km}$ domain, (top row) base climate, (middle row) 2020-2030, and, (bottom row) 2045-2055. Density is defined as the number of cyclone tracks or genesis points within a 5 degree radius of a point per year. Non-normalized track and genesis densities are provided in the SOM section S4 

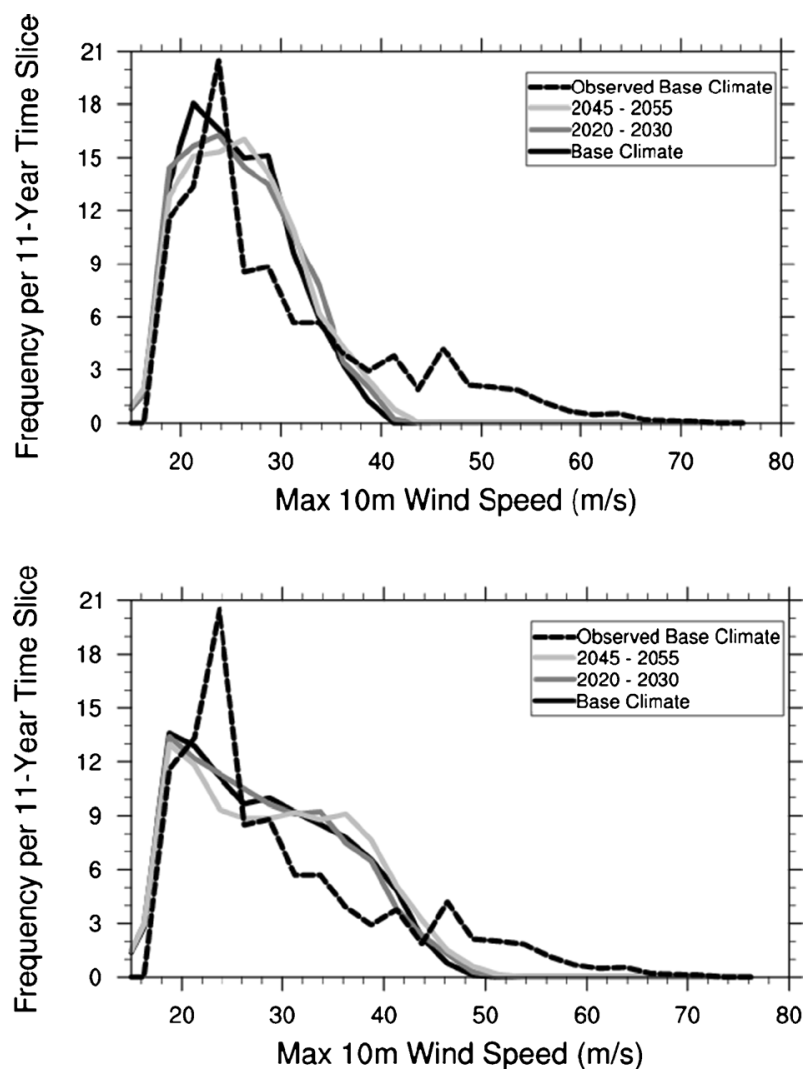

Fig. 5 Frequency distributions of 6-hourly tropical cyclone maximum wind speed $\left(\mathrm{ms}^{-1}\right)$ at $10 \mathrm{~m}$ above the surface as simulated by the NRCM (top) $36 \mathrm{~km}$ domain and (bottom) $12 \mathrm{~km}$ domain for base climate (black line), the period 2020-2030 (dark gray), and the period 2045-2055 (light gray), and observations (IBTrACS data) for the period 1995-2005 (black dashed line). Adapted from Holland et al (2010). Copyright 2010 OTC. Reproduced with permission of the copyright owner

held back in this region. Nevertheless, storms on the $36 \mathrm{~km}$ and $12 \mathrm{~km}$ domains experience modest future increases in mean wind speed of approximately $0.64 \mathrm{~ms}^{-1}$ and $0.90 \mathrm{~ms}^{-1}$ respectively. This increase is less than observational errors in the historical record; meaning current observation systems could not detect this change in the mean intensity.

A more marked increase, however, is seen in the number and intensity of the most intense hurricanes that can be resolved by the model (Fig. 5). This is in agreement with other dynamical modeling and theoretical studies (Knutson et al. 2010) and for recent changes to current climate (Holland and Bruyère 2013). These intensity increases may be due to future large-scale environment changes (indeed, Suzuki-Parker (2012) showed favorable future increases in SST, relative SST (Vecchi and Soden (2007) and decreasing shear in the driving CCSM data) but may also be due to the future southeastward shift of track density (Fig. 4) associated with potential changes in the proportion of tropical cyclones developing from easterly waves and cyclone track lengths. 


\section{Statistical assessments}

Confidence in the variability and trends of high-impact events obtained through dynamical downscaling is limited in part by the relatively short period and small number of events that can be simulated. Fortunately, sample size can be increased substantially through statistical approaches and can aid uncertainty assessments. Such statistical assessments provide a valuable adjunct to the dynamical simulations and by way of illustration two approaches are discussed here.

\subsection{Empirical assessments of tropical cyclone frequency}

A popular statistical downscaling approach for tropical cyclone frequency is the use of empirical relationships with large-scale data taken from reanalysis or global model data (e.g. Gray 1968, 1984; Emanuel and Nolan 2004). These approaches were typically designed to capture the hemispheric seasonal cycle and typically do not do well on regional and interannual scales. For example, Menkes et al. (2011) applied four genesis potential indices to different reanalysis datasets and found poor reproduction of interannual amplitude and phase variability on regional scales. However, recent work has begun to show skill on regional, seasonal scales.

The Emanuel and Nolan (2004) index combines low-level vorticity, mid-level relative humidity, potential intensity (a measure of the vertical instability of the atmosphere, Emanuel 2000), and vertical wind shear. Bruyère et al. (2012) showed that for interannual variability and longer-term changes, the relative humidity and vorticity terms contribute nothing to the skill, though this could be due to the specific formulation of the index rather than having a physical interpretation (a general limitation highlighted by Menkes et al. 2011). Bruyère et al. (2012) also found care needs to be taken when selecting an index averaging area: for the North Atlantic, a basin-wide average was not optimal in explaining total basin cyclone frequency, whereas an average taken over the eastern tropical Atlantic $\left(5-20^{\circ} \mathrm{N}, 60-15^{\circ} \mathrm{W}\right)$, was able to explain $72 \%$ of the annual variance of total basin cyclone frequency.

Suzuki-Parker (2012) applied the Bruyère et al. (2012) index to the same revised global data used to drive the NRCM simulations presented in Section 2 and produced results in agreement with the NRCM dynamical results of an increase in tropical cyclone frequency of between 1 and 3 storms by the mid $21^{\text {st }}$ century.

\subsection{Extreme value assessment of tropical cyclone intensity}

One complimentary approach to assess changes to the most intense cyclones from the truncated regional climate simulations is to utilize extreme value statistics (Coles 2001). The NRCM-generated cyclone intensity distribution is truncated at maximum winds of around $43 \mathrm{~ms}^{-1}$ for tropical cyclones on the $36 \mathrm{~km}$ grid (Fig. 5). However, as stated earlier the NRCM predicts a shift of the truncated distribution towards more intense storms over the next 50 years (Fig. 5). Applications of the Weibull distribution (Weibull 1939) have been experimented with to assess associated changes in the intense cyclones. The Weibull is a stretched exponential distribution and is used here because of its history of application to modeling weather and climate extremes (e.g. Katz and Brown 1992; Mearns et al. 1984) and because it is bounded below at zero.

The Weibull Cumulative Distribution Function (CDF) and Probability Density Function (PDF) are: 


$$
\begin{gathered}
C D F: F(x)=1-e^{-\left(\frac{x}{\alpha}\right)^{\beta}}, 0 \leq x \leq \infty \\
P D F: f(x)=\frac{\partial F(x)}{\partial x}=\frac{\beta}{\alpha}\left(\frac{x}{\alpha}\right)^{\beta-1} e^{-\left(\frac{x}{\alpha}\right)^{\beta}}, 0<x<\infty
\end{gathered}
$$

The scale parameter $\alpha$ and the shape parameter $\beta$ both lie in the range $(0, \infty): \beta=1$ corresponds to the exponential distribution, $\beta=2$ the Rayleigh distribution, and $\beta=3.5$ an approximation of the normal distribution. The mean and the variance of the Weibull distribution are given by:

$$
\begin{gathered}
\text { Mean : } \mu=\alpha \Gamma\left(1+\frac{1}{\beta}\right) \\
\text { Variance: } \sigma^{2}=a^{2} \Gamma\left(1+\frac{2}{\beta}\right)-\mu^{2},
\end{gathered}
$$

where $\Gamma$ is the Gamma function. Thus, a first-order approximation to future changes in tropical cyclone extremes can be obtained by first applying the Weibull to current tropical cyclones for the period 1995-2008 (where $x$ in Eqs. 4 and 5 corresponds to cyclone lifetime maximum $10 \mathrm{~m}$ wind speed, using IBTrACS, Knapp et al. 2010) to obtain current scale parameter $\alpha=37$ and shape parameter $\beta=1.8$ using the method of moments. Model-resolved future changes in the mean and standard deviation of tropical cyclone intensity are then used to estimate changes to these current scale and shape parameters and provide an assessment of future full intensity distributions. Finally, the changes in probability of various tropical cyclone intensities can be calculated from the Weibull exceedence probability:

$$
P(x>c)=1-F(c)=e^{-\left(\frac{c}{\alpha}\right)^{\beta}},
$$

where $\mathrm{c}$ is the lower limit of the intensity range of interest (e.g. $69 \mathrm{~ms}^{-1}$ for Cat 5 hurricanes).

The small $36 \mathrm{~km}$ NRCM-predicted changes in the resolved distribution result in a much greater change in the most intense cyclones (Fig. 6). Category 5 hurricanes are predicted to increase by $60 \%$ from a base climate period of 1980-1994 and by $30 \%$ from a base climate period of 1995-2008. In this application we make the assumptions that the modeled changes are indicative of the changes that would have been simulated in the full distribution, were it resolved;
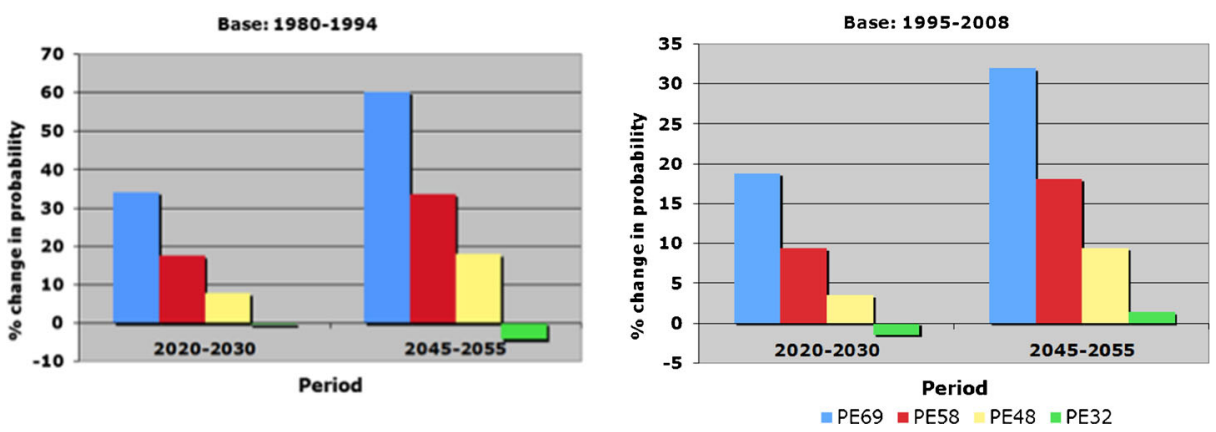

Fig. 6 Future changes to all hurricanes (green), category 3-5 (yellow), category 4-5 (red) and category 5 (blue), using a base climate of: 1980-1994 (left) and 1995-2008 (right) 
and there is no process that will cause a change in the unresolved tail of the distribution without any signal in the resolved component.

Another approach is to further dynamically downscale the NRCM to a resolution capable of resolving the full intensity distribution. Bender et al. (2010) took this approach using the Geophysical Fluid Dynamics Laboratory operational hurricane model to downscale to a resolution that captured the full intensity distribution and showed similar future changes to the most intense storms as reported here. This suggests that the statistical correction of the intensity distribution is a promising line of research that warrants further exploration, particularly with regard to understanding how the model intensity distribution relates to the observed intensity distribution.

\section{Concluding discussion}

This discussion of dynamical and statistical approaches to assessing variability and change in high-impact weather events is intended to contribute to community discussion and collaboration on best practices. Key findings are:

1) Importance of domain size, location and resolution: These aspects of model setup need careful consideration in order to capture accurate regional climate and high-impact weather. Experience with the NRCM using large domains at different resolutions indicates that: higher resolution than is required to resolve the key characteristics of the high-impact events may produce little added value and may not be an optimal use of resources; and, to capture accurate regional climate and regional climate change the regional domain may need to include those forcings and circulations that directly affect the regional climate over the area of interest.

2) Treating bias: Regional climate simulations can be severely affected by biases in the driving global climate model, even when large domains are employed. A successful technique has been shown to remove such bias in a manner that retains the day-to-day weather, climate variability and change components. As climate models improve, there remains a need to treat regional biases (e.g. Muñoz et al. 2012). Further work is required to fully understand the implications of such techniques, to assess and remove changes in bias with time, and to develop new approaches to bias removal for emerging modeling tools such as regional atmosphere-ocean coupled models and global variable resolution meshes.

3) Incorporating statistics and assessing uncertainty: Confidence in high-impact weather assessments obtained through dynamical downscaling is limited by both truncation of the observed distribution and the small number of events that can be simulated. Ensemble modeling is an obvious approach to increase sample size and explore statistical uncertainty. Indeed, Strachan et al (2013) show spread in annual TC counts in a small initial condition ensemble global atmospheric model, but this approach is computationally impractical for high resolution, large domains. The examples of empirical and extreme value approaches discussed here serve to demonstrate the high potential of combining dynamical modeling with statistical approaches in assessing high-impact weather. Their value lies in both assessments of events beyond the capacity of current dynamical models and the effective increase in sample size by the ability to use low-resolution ensembles. These lead to improved assessments of statistical uncertainty in the climatology of high-impact weather and future change. 
Meeting the societal demand for assessments of variability and change in high-impact weather events with regional clarity is a challenge that extends well beyond simply improving climate simulations, and once the regional climate prediction has been made and the uncertainty quantified, there remains a huge gap regarding how this affects society. The past two decades of regional climate research outputs have largely been exploratory in nature and not directly aligned to the requirements of the end user. Exceptions include ensemble regional downscaling programs and bias corrected and statistically downscaled CMIP3 archives. Recent work by Towler et al (2012) went a step further by incorporating NRCM-generated climate change data into a risk-based approach to assess ecological impacts and inform conservation efforts. The field is wide open to develop the concepts discussed here further and to more fully integrate with societal impact assessments.

Acknowledgments NCAR is funded by the National Science Foundation and this work was partially supported by the Willis Research Network, the Research Partnership to Secure Energy for America, and the Climatology and Simulation of Eddies/Eddies Joint Industry Project. LRL was supported by the Department of Energy Regional and Global Climate Modeling and Integrated Assessment Research programs. The Pacific Northwest National Laboratory is operated for DOE by Battelle Memorial Institute under contract DE-AC05-76RLO1830. This research used resources of the Argonne Leadership Computing Facility at Argonne National Laboratory, which is supported by the Office of Science of the U.S. Department of Energy under contract DE-AC02-06CH11357. The ideas and concepts benefitted from discussions with: Julie Caron, Bill Collins, Cort Cooper, Rowan Douglas, Sherrie Fredrick, Jim Hack, Jim Hurrell, Rick Katz, Bill Kuo, Bill Large, John Michalakes, Adam Phillips, Erin Towler, Joe Tribbia, Mariana Vertenstein and Jon Wolfe.

Open Access This article is distributed under the terms of the Creative Commons Attribution License which permits any use, distribution, and reproduction in any medium, provided the original author(s) and the source are credited.

\section{References}

Bender MA, Knutson TR, Tuleya RE, Sirutis JJ, Vecchi GA, Garner ST, Held IM (2010) Modeled impact of anthropogenic warming on the frequency of intense Atlantic hurricanes. Science 22:454-458

Bengtsson L, Hodges KI, Esch M, Keenlyside N, Kornblueh L, Luo J-J, Yamagata T (2007) How may tropical cyclones change in a warmer climate. Tellus 59A:539-561

Bruyère CL, Holland GJ, Towler E (2012) Investigating the use of a genesis potential index for tropical cyclones in the North Atlantic Basin. J Clim 25(24):8611-8626

Camargo SJ, Sobel AH, Barnston AG, Emanuel KA (2007) Tropical cyclone genesis potential index in climate models. Tellus 59A:428-443

Caron L-P, Jones CG (2011) Understanding and simulating the link between African Easterly Waves and Atlantic Tropical Cyclones using a Regional Climate Model: the role of domain size and lateral boundary conditions. Clim Dyn. doi:10.1007/s00382-011-1160-8

Caron L-P, Jones CG, Winger K (2010) Impact of resolution and downscaling technique in simulating recent Atlantic Tropical Cyclone Activity. Clim Dyn. doi:10.1007/s00382-010-0846-7

Coles S (2001) An introduction to statistical modeling of extreme values. Springer, London, $208 \mathrm{pp}$

Collins WD, Bitz CM, Blackmon ML, Bonan GB, Bretherton CS, Carton JA, Chang P, Doney SC, Hack JJ, Henderson TB, Kiehl JT, Large WG, McKenna DS, Santer BD, Smith RD (2006) The community climate system model version 3 (CCSM3). J Clim 19:2122-2143

Davis C et al (2008) Prediction of landfalling hurricanes with the advanced hurricane WRF model. Mon Weather Rev 136:1990-2005

Davis C, Wang W, Cavallo S, Done J, Dudhia J, Fredrick S, Michalakes J, Caldwell G, Engel T, Ghosh S, Torn R (2010) High-resolution hurricane forecasts. Computing in Science and Engineering, CISESI-2010-03-0023

Done J, Holland GJ, Bruyère C, Suzuki-Parker A (2011) Effects of climate variability and change on Golf of Mexico Tropical Cyclone Activity. Paper OTC 22190 presented at the Offshore Technology Conference, Houston, Texas, 2-5 May 
Dosio A, Paruolo P (2011) Bias correction of the ENSEMBLES high-resolution climate change projections for use by impact models: Evaluation on the present climate. J Geophys Res 116, doi:10.1029/ 2011JD015934

Emanuel KA (2000) A statistical analysis of tropical cyclone intensity. Mon Weather Rev 128:1139-1152

Emanuel K, Nolan DS (2004) Tropical cyclone activity and global climate. In: Proc. of 26th Conference on Hurricanes and Tropical Meteorology, American Meteorological Society, Miami, FL, pp 240-241

Gentry MS, Lackmann GM (2010) Sensitivity of simulated tropical cyclone structure and intensity to horizontal resolution. Mon Weather Rev 138:688-704

Giorgi F, Mearns L (1999) Introduction to special section: regional climate modeling revisited. J Geophys Res 104(D6): doi:10.1029/98JD02072

Gray WM (1968) Global view of the origin of tropical disturbances and storms. Mon Weather Rev 96:669-700

Gray WM (1984) Atlantic seasonal hurricane frequency. Part I: El Niño and $30 \mathrm{mb}$ Quasi-Biennial Oscillation influences. Mon Weather Rev 112:1649-1668

Holland GJ, Bruyère CL (2013) Recent intense hurricane response to global climate change. Clim Dyn. doi:10.1007/s00382-013-1713-0

Holland GJ, Webster PJ (2007) Heightened tropical cyclone activity in the North Atlantic: natural variability or climate trend? Phil Trans R Soc A. doi:10.1098/rsta.2007.2083

Holland GJ, Done JM, Bruyère CL, Cooper C, Suzuki A (2010) Model investigations of the effects of climate variability and change on future Gulf of Mexico Tropical Cyclone Activity. Paper OTC 20690 presented at the Offshore Technology Conference, Houston, Texas, 3-6 May

IPCC SRES SPM (2000) Summary for policymakers, emissions scenarios: a special report of IPCC Working Group III, IPCC, ISBN 92-9169-113-5

Jones RG, Murphy JM, Noguer M (1995) Simulation of climate change over Europe using a nested regionalclimate model. I: Assessment of control climate, including sensitivity to location of lateral boundaries. Quart J Roy Meteor Soc 121:1413-1449

Kalnay E et al (1996) The NCEP/NCAR 40-year reanalysis project. Bull Am Meteorol Soc 77:437-477

Katz RW (2010) Statistics of extremes in climate change. Clim Chang 100:71-76

Katz RW, Brown BG (1992) Extreme events in a changing climate: variability is more important than averages. Clim Chang 21:289-302

Kieu CQ, Zhang D-L (2008) Genesis of Tropical Storm Eugene (2005) from merging vortices associated with the ITCZ breakdowns. Part I: Observational and modeling analyses. J Atmos Sci 65:3419-3439

Knapp K, Kruk M, Levinson D, Diamond H, Neumann C (2010) The international best track archive for climate stewardship (IBTrACS). Bull Am Meteorol Soc 91:363-376

Knutson TR, Sirutis JJ, Garner ST, Held IM, Tuleya RE (2007) Simulation of the recent multidecadal increase of Atlantic hurricane activity using an 18-km-grid regional model. Bull Am Meteorol Soc 88:1549-1565

Knutson T, Sirutis JJ, Garner ST, Vecchi G, Held IM (2008) Simulated reduction in Atlantic hurricane frequency under twenty-first-century warming conditions. Nat Geosci 1(6):359-364

Knutson TR, McBride JL, Chan J, Emanuel K, Holland G, Landsea C, Held I, Kossin JP, Srivastava AK, Sugi M (2010) Tropical cyclones and climate change. Nat Geosci 3:157-163

Kumar A, Done JM, Dudhia J, Niyogi D (2011) Simulations of cyclone Sidr in the Bay of Bengal with a highresolution model: sensitivity to large-scale boundary forcing. Meteor Atmos Physics. doi:10.1007/s00703011-0161-9

Kunreuther H, Michel-Kerjan E (2009) At war with the weather: managing large-scale risks in a new era of catastrophes. MIT Press, New York, p 416

Laprise R, de Elía R, Caya D, Biner S, Lucas-Picher P, Diaconescu EP, Leduc M, Alexandru A, Separovic L (2008) Challenging some tenets of regional climate. Modelling Meteor Atmos Phys 100:3-22. doi:10.1007/ s00703-008-0292-9

Large WG, Danabasoglu G (2006) Attribution and impacts of upper ocean biases in CCSM3. J Clim 19:2325-2346

Leduc M, Laprise R (2009) Regional climate model sensitivity to domain size. Clim Dyn 32(6):833-854

Leung LR, Kuo YH, Tribbia J (2006) Research needs and directions of regional climate modeling using WRF and CCSM. Bull Am Meteorol Soc 87(12):1747-1751

Mearns LO, Katz RW, Schneider SH (1984) Extreme high-temperature events: changes in their probabilities with changes in mean temperature. J Clim Appl Meteorol 23:1601-1613

Meehl GA, Covey C, Taylor KE, Delworth T, Stouffer RJ, Latif M, McAvaney B, Mitchell JFB (2007) The WCRP CMIP3 multimodel dataset: a new era in climate change research. Bull Am Meteorol Soc 88:13831394. doi:10.1175/BAMS-88-9-1383

Menkes CE, Lengaigne M, Marchesiello P, Jourdain NC, Vincent EM, Lefèvre J, Chauvin F, Royer JF (2011) Comparison of tropical cyclogenesis indices on seasonal to interannual timescales. Clim Dyn 38:301-321

Mote PW, Brekke L, Duffy P, Maurer E (2011) Guidelines for constructing climate scenarios. Eos Trans AGU $92: 31$ 
Muñoz E, Weijer W, Grodsky S, Bates SC, Wainer I (2012) Mean and variability of the tropical Atlantic Ocean in the CCSM4. J Clim 25:4860-4882

Rasmussen R et al (2011) High-resolution coupled climate runoff simulations of seasonal snowfall over Colorado: a process study of current and warmer climate. J Clim 24:3015-3048. doi:10.1175/2010JCLI3985.1

Schär C, Frie C, Lüthi D, Davies HC (1996) Surrogate climate-change scenarios for regional climate models. Geophys Res Lett 23:669-672

Skamarock W, Klemp J, Dudhia J, Gill D, Barker D, Wang W, Powers J (2008) A description of the advanced research WRF version 3. NCAR Technical Note 475. $113 \mathrm{pp}$

Strachan J, Vidale PL, Hodges K, Roberts M, Demory M-E (2013) Investigating global tropical cyclone activity with a hierarchy of AGCMs: the role of model resolution. J Clim 26:133-152

Suzuki-Parker A (2012) An assessment of uncertainties and limitations in simulating tropical cyclones. Springer Thesis. XIII, $78 \mathrm{pp}$

Towler E, Saab V, Sojda R, Dickinson K, Bruyère C, Newlon KR (2012) A risk-based approach to evaluating wildlife demographics for management in a changing climate: A case study of the Lewis's Woodpecker. Environ Manage 50(6):1152-1163. doi:10.1007/s00267-012-9953-z

Vannitsem S, Chome F (2005) One-way nested regional climate simulations and domain size. J Clim 18:229-233

Vecchi G, Soden B (2007) Effect of remote sea surface temperature change on tropical cyclone potential intensity. Nature 450(7172):1066-1070

Weibull W (1939) A statistical theory of the strength of material. Proc Roy Swedish Inst Eng Res 151:1

Wilks DS (2006) Statistical methods in the atmospheric sciences, 2nd edn. International Geophysics Series, Vol 91, Academic Press

Wu L, Tao L, Ding Q (2010) Influence of sea surface warming on environmental factors affecting long-term changes of Atlantic tropical cyclone formation. J Clim 23:5978-5989

Xu Z, Yang Z-L (2012) An improved dynamical downscaling method with GCM bias corrections and its validation with 30 years of climate simulations. J Clim 25:6271-6286 